\title{
Letramento dominante $\mathrm{x}$ vernacular e suas implicações para o ensino da literatura
}

\section{Dominant literacy $\mathrm{x}$ vernacular literacy and its implications on literary teaching}

\section{Mirian Hisae Yaegashi Zappone* \\ Universidade Estadual de Maringá \\ Ibrahim Alisson Yamakawa** \\ Universidade Estadual de Maringá}

Resumo: Os recentes estudos sobre letramento representam uma significativa mudança na forma como se deve compreender o fenômeno da leitura e da escrita nos mais diferentes contextos. Falar de letramento consiste em lidar com uma realidade complexa na qual vários agentes estão envolvidos e onde cada contexto requer uma nova apropriação da escrita. Nesse sentido, pode-se depreender que existem múltiplas formas de desenvolver-se o letramento, e a leitura literária é uma delas. Entretanto, como lembra Roxane Rojo (2009), não são todos os letramentos considerados pela cultura oficial. Ao mesmo tempo, observa-se que práticas de letramento locais são desvalorizadas diante das práticas que se alinham à cultura letrada. E o mesmo acontece com as práticas de leitura literária efetivadas pelos próprios alunos fora da escola. Baseando-se em entrevistas realizadas com 27 alunos de uma escola pública de ensino médio da cidade de Maringá -PR, observou-se que os alunos leem textos ficcionais, mas os textos por eles lidos não são considerados pela escola. Por essa razão, cria-se um desconforto em relação às aulas de literatura. Partindo do conceito de letramento literário, proposto por Zappone (2007), este trabalho pretende discutir a especificidade da leitura literária no contexto escolar, bem como examinar o choque entre os letramentos trazidos pelos estudantes e os letramentos dominantes e analisar sua consequência para o ensino de literatura.

Palavras-chave: Letramento literário. Leitura literária. Letramento crítico.

Abstract: Recent studies on literacy represent a significant change in how one should understand the phenomenon of reading and writing in many different contexts. Speaking of literacy is to deal with a complex reality and plurissignificativo where several agents are involved and where each context requires a new appropriation of writing. In this sense, we can deduce that there are multiple ways to develop literacy. And literary reading is one of them. However, as noted by Roxane Rojo (2009), all literacies are not considered by the official culture. This means that literacy practices are devalued by local literary culture. And the same happens with the practical effect of literary reading by students outside of school. Based on interviews with students from a public school in high school in the city of Maringá-PR, it was observed that students read literature, but the texts they read

\author{
* Professora associada \\ do Departamento de \\ Teorias Linguísticas \\ e Literárias e do \\ Programa de Pós- \\ graduação em Letras \\ da Universidade \\ Estadual de \\ Maringá. Contato: \\ mirianzappone@ \\ gmail.com \\ ** Aluno do Curso de \\ Letras-Habilitação \\ Inglês e bolsista \\ do Programa de \\ Bolsas de Iniciação \\ à Docência \\ (PIBID-Letras) \\ da Universidade \\ Estadual de \\ Maringá. Contato: \\ alissonyamakawa@ \\ hotmail.com
}


are not considered by the school, and therefore creates a discomfort in relation to literature classes. Based on the concept of literary literacy proposed by Zappone (2007), this paper discusses the specificity of literary reading in schools, as well as examine the clash between literacies brought by students and dominant literacies and analyze its consequences for teaching literature.

Keywords: Literary literacy. Literary reading. Critical literacy.

\section{Introdução}

Em uma sociedade em que a escrita se torna uma ferramenta primordial para as práticas comunicativas, ser letrado é condição crucial para participar efetivamente dos eventos de letramento, ou seja, interagir socialmente usando a escrita. E esta, sendo um produto social e historicamente determinado possui significados distintos em cada contexto. Os estudos sobre letramento, por sua vez, estão preocupados, justamente, sobre os efeitos e os significados que a leitura e a escrita possui para grupos sociais distintos. Os novos estudos sobre os letramentos buscam responder quais os significados as práticas de leitura e da escrita tem para as comunidades envolvidas, mas para tanto, é preciso que se compreenda o letramento enquanto prática social.

O conceito de letramento proposto por Kleiman (2004a) ilustra bem como simples práticas cotidianas podem constituir eventos de letramento, pois segundo a autora, define-se letramento como "um conjunto de práticas sociais que usam a escrita, enquanto sistema simbólico e enquanto tecnologia, em contextos específicos, para objetivos específicos.” (KLEIMAN, 2004a, p.19). Nessa perspectiva, qualquer interação social em que a escrita esteja presente se configura como prática de letramento.

Entendendo, portanto, que os estudos sobre letramento estão centrados em práticas cotidianas que envolvem as atividades de leitura e de escrita, podemos inferir que a leitura de textos literários também está entre essas práticas cotidianas. Estas, por sua vez, são entendidas como práticas de letramento literário, conforme definido por Zappone (2007), pois usam a escrita literária em contextos específicos e com objetivos específicos. Por esta razão, produzem efeitos distintos para grupos de leitores variados. A abrangência desse conceito permite perceber que as práticas de letramento literário são inúmeras e com objetivos múltiplos.

Todavia, o letramento literário ocorre mais frequentemente no contexto escolar. Na escola, definida por Kleiman (2004a) como um a das principais agências de letramento, já que seus modos de leitura são regulados e preveem agentes específicos, realiza-se um modo muito particular de leitura de textos literários. Neste caso, focaliza-se o texto escrito e a ele atribui-se a concepção de autonomia, concepção segundo o qual o texto escrito é tido como completo em si mesmo, independente dos contextos de seu uso. 
Desenvolver o letramento literário no ambiente escolar significa se apropriar de um modo muito específico de leitura, chamada de leitura literária. Esta é caracterizada pela adoção de certos procedimentos muito particulares do contexto escolar, a leitura literária é regulada, por exemplo, pelo reconhecimento do gênero, do estilo, informações sobre o autor, sobre o contexto etc.

Entretanto, essa não é a única forma de desenvolver o letramento literário. Isso se trata de uma especificidade prevista unicamente no contexto escolar e acadêmico. Além dos muros escolares, existem inúmeras práticas de letramento literário, porém em contextos menos formais onde a especificidade da leitura literária é apagada. Por esta razão, o conceito de letramento literário proposto por Zappone (2007), é extremamente relevante no que se refere a questões relativas ao ensino de literatura.

O conceito de letramento literário aplicado ao ensino de literatura amplia a perspectiva de como a leitura de literatura deve ser encarada, pois, permite compreender que há um letramento literário escolar formal, regido por normas e convenções de leitura e há outro letramento literário, o social. As práticas de letramento literário, nesse sentido, seriam incalculáveis ao estender o fenômeno do letramento literário para além dos bancos escolares.

Como lembra Rojo (2009), o letramento passa a ser um conceito plural. As práticas de letramento, consequentemente, seriam variáveis no tempo e no espaço, havendo práticas de letramento valorizadas e não valorizadas, letramentos dominantes e letramentos vernaculares. E a escola, sendo a principal agência de letramento, cujo objetivo seria possibilitar a participação democrática de seus alunos nas várias práticas sociais que utilizam a escrita, acaba sendo um espaço de exclusão e apagamento de outras formas de letramento. "Isso cria uma situação de conflito entre práticas letradas valorizadas e não valorizadas na escola” (ROJO, 2009, p.106). Assim, como completa Rojo, essas mudanças mostram que a escola de hoje é um universo múltiplo onde convivem letramentos muito diferenciados, no entanto, sempre em conflito, pois na medida em que uns são enfatizados, outros são ignorados.

Com o letramento literário, verifica-se a mesma situação. Que impacto tal fato tem para as aulas de literatura no Ensino Médio? Com base em observação e entrevistas feitas com alunos do Ensino Médio de um colégio público de Maringá, objetivou-se compreender que efeitos as práticas de letramento literário efetivadas pelos alunos, sem mediação de um professor ou outro agente de letramento, tem para o ensino de literatura e para o desenvolvimento do grau de letramento dos sujeitos. E quais implicações as leituras de textos literários não patrocinadas pela escola tem para as aulas de literatura. 


\section{O conceito de letramento literário}

Para tratar do conceito de letramento literário, conforme Zappone (2007), faz-se necessário apresentar algumas especificidades do conceito de letramento. O conceito de letramento literário proposto pela autora deriva do conceito de letramento definido por Kleiman (2004a) e Rojo (2009). As autoras concebem o termo letramento enquanto práticas sociais em que a escrita está envolvida num papel fundamental para a intrelocução entre os sujeitos:

O letramento é aqui considerado como um conjunto de práticas sociais, cujos modos específicos de funcionamento têm implicações importantes para as formas pelas quais os sujeitos envolvidos nessas práticas constroem relações de identidade e poder. (KLEIMAN, 2004a, p. 11).

Ao considerar esta conceituação de Kleiman (2004a), as práticas de letramento estão ligadas aos contextos em que estas são desenvolvidas, observando-se que em cada contexto é pressuposto que os sujeitos desenvolvam o letramento de uma forma muito específica para construir sentido. A autora lembra que, quando as condições mudam, as formas de se apropriar da escrita também mudam. Além disso, ela afirma que em tais práticas estão implicadas a relações de identidade e poder.

Street (1984) elucida essa relação quando propõe a existência de dois enfoques de letramento distintos. $\mathrm{O}$ autor afirma que diferentes formas de letramento são ideologicamente demarcadas por relações de poder e autoridade. Nesse sentido, Street (1984) postula o enfoque de letramento autônomo, modelo dominante na sociedade, que se relaciona à mentalidade progressista de educação em massa, de modo que as especificidades de cada contexto são dispensáveis. Por isso, o autor concebe, neste modelo, a escrita enquanto um produto completo em si mesmo independente dos contextos de produção e recepção. A escrita seria invariável, fazendo da leitura um processo de decodificação do texto obedecendo à lógica interna imanente ao texto. Segundo ele, nesse enfoque, a escrita pode ser transposta no tempo e no espaço sem sofrer variações e deformações. A habilidade da escrita e da leitura requer, então, o domínio de uma habilidade bastante especifica, na qual o sujeito pode extrair o significado dentro das fronteiras onde este significado está explicito: o texto em si.

Entretanto, o autor também propõe um modelo alternativo em relação ao modelo autônomo, chamado por ele de modelo ideológico de letramento. Este, ao contrário do autônomo, concebe todas as práticas sociais que utilizam a escrita, além de considerar os contextos de produção e de recepção, pois as práticas de letramento não são neutras. De tal forma, o enfoque ideológico "vê as práticas de letramento como indissoluvelmente ligadas às estruturas culturais e de poder da sociedade e reconhece a 
variedade de práticas culturais associadas à leitura e a escrita em diferentes contextos" (ROJO, 2009, p. 99). Como se pode notar, esses dois enfoques são fundamentais para a compreensão do conceito de letramento literário. Ao pensar o conceito de letramento literário como

práticas que usam a escrita literária, pensada como um gênero de discurso que pressupõe a ficcionalidade como traço principal, é possível observar letramento literário em inúmeros outros espaços que não apenas a escola. Assim, constituem práticas de letramento literário a audiência de novelas, séries, filmes televisivos, o próprio cinema, em alguns casos a internet, a contação de histórias populares, de anedotas etc. (ZAPPONE, 2008, p. 31).

Este conceito pressupõe a interação com a escrita literária como prática de letramento literário, ao mesmo tempo que implica a compreensão da escrita literária como aquela cujo traço definidor seria seu caráter de ficcionalidade. Como a própria autora elenca, há diversas formas de participar de um evento de letramento literário, contudo, conforme já foi mencionado anteriormente, há práticas de letramento valorizadas e outras menos valorizadas. Na escola, por sua vez, prevalece o modelo autônomo de letramento e este desconsidera os contextos e ignora a diversidade das práticas de letramento. A escrita seria autônoma e independente, seria suficiente por ela mesma para a produção de sentido. Ao mesmo tempo, nesta concepção autônoma, os textos eleitos pela escola como dignos de serem lidos deveriam ter o mesmo significado para todos os leitores.

No caso da escrita literária, a noção de autonomia, conforme explica Zappone (2010), seria muito mais evidente, visto que, no contexto escolar, a leitura dos textos literários estaria diretamente ligada às normas internas que regem o texto literário. Assim, para interagir efetivamente nessa prática de letramento escolar, é necessário identificar e interpretar as normas que compõem os textos literários. A leitura literária se caracteriza pela adoção de certos procedimentos que fazem com que o leitor interaja com os processos estéticos que emergem do texto. Para haver compreensão de uma obra literária nos modos previstos pela agência escolar, deve-se levar em consideração todos os fatores que circundam sua produção, tais como o estilo de época segundo o qual ela foi produzida, os contextos histórico, social e político nos quais se insere, fatores individuais ou aspectos relacionados ao autor, sua inserção na história, as marcas individuais de criação literária, seus aspectos biográficos e, por último, o texto e seus aspectos textuais propriamente ditos. Então, como afirma Hansen:

Para que uma leitura se especifique com leitura literária é consensual que o leitor deva ser capaz de ocupar a posição semiótica de destinatário do texto, refazendo os processos autorais de invenção que produzem o efeito de fingimento, o leitor deve coincidir com o destinatário do texto para receber a informação de modo adequado. (HANSEN, 2005, p.19-20). 
Como se pode notar, a leitura literária esperada pela agência escolar se refere a uma habilidade de leitura muito específica e especializada. Geralmente, para os alunos, a leitura de textos literários na escola se torna uma atividade densa e complexa, alheia as suas práticas de letramento literário usuais. De fato, grande parte das atividades valorizadas na vida cotidiana das pessoas é desvalorizada pelas instituições educacionais e não conta como letramento verdadeiro. Perde-se a oportunidade de aproveitar essas formas de letramento praticadas na vida cotidiana como ferramentas de condução e assimilação das formas mais valorizadas, como é o caso da leitura literária.

\section{O choque entre letramentos dominantes e vernaculares no contexto escolar}

Com base nas considerações feitas por Kleiman (2004a), Rojo (2009) e Hamilton (2010), observa-se que a escola ser torna um espaço para o choque entre os letramentos. Hamilton (2010) propõe a concepção de "letramentos dominantes", que se aplica ao contexto escolar, pois estão relacionados à cultura letrada, são os letramentos institucionalizados e padronizados. No caso, os letramentos dominantes se oporiam aos letramentos vernaculares, pois se configuram enquanto práticas não formalizadas e muitas vezes consideradas ilegítimas.

Com o intuito de formar leitores literários, a escola enfatiza um modelo em detrimento do outro, desconsiderando a heterogeneidade do ambiente, dos sujeitos e dos múltiplos letramentos que lá convivem. Dentro da perspectiva dos múltiplos letramentos, espera-se que os alunos possam integrar as suas práticas sociocomunicativas às práticas desenvolvidas no ambiente escolar. Porém, conforme aponta Rojo (2009), há um apagamento total dos letramentos trazidos pelos alunos. Estes, por sua vez, não permanecem neutros nesse movimento. Eles continuam desenvolvendo as suas práticas de letramento, inclusive as suas práticas de letramento literário. E estas práticas realizadas por eles aparecem no ambiente escolar como uma forma de revide em relação aos modos enfatizados pela escola, como afirma Rojo (2009): são formas de resistência por parte dos alunos. Esse choque entre os letramentos tem um efeito sobre os alunos em relação às aulas de literatura.

Cria-se, assim, um desconforto em relação às aulas de literatura, pois a escola espera que os alunos leiam uma literatura com a qual estes não estão familiarizados e com certo grau de especificidade que eles não conhecem. Além disso, os estudantes não fazem relação alguma com as atividades propostas pela escola e as atividades por eles realizadas fora da escola. Consequentemente, as práticas letradas propostas pela agência escolar não são retidas pelos alunos. Em função do choque entre os letramentos, os estudantes se encontram mais resistentes às práticas letradas institucionalizadas. 


\section{Os efeitos dos choques entre letramentos no contexto escolar}

Diante dessas considerações, por meio de entrevistas realizadas com alunos de $1^{\circ}$ anos de Ensino Médio de um colégio público de Maringá, o Colégio Estadual Doutor Gastão Vidigal, constatou-se o choque existente entre os letramentos escolares e os letramentos não escolares, e isto se tornou um fator dificultador para o ensino de literatura. Os alunos foram submetidos a um questionário, a fim identificar o seu envolvimento com as aulas de literatura na escola, pois segundo Kleiman (2004b), o professor precisa estar capacitado para ser um verdadeiro agente de letramento, ser capaz de reconhecer o valor e o significado da escrita na vida do seu aluno.

O questionário procurou observar se os alunos participam dos eventos de letramento literário propostos pelo professor, como também de eventos de letramento literário fora da escola. Também se procurou observar com que intensidade os alunos participam das aulas de literatura, isto é, se eles leem as obras solicitadas pela escola e se eles reconhecem a importância da disciplina literatura na grade curricular. Primeiramente, os alunos foram questionados sobre os seus hábitos de leitura, a respeito do que leem e dos tipos de textos lidos. Depois, foram questionados sobre seu interesse pela leitura de textos ficcionais no contexto escolar e em contextos informais, por meio de citação de suas três últimas leituras. Eles também responderam sobre dificuldades ou não encontradas na disciplina de literatura. Os questionários foram elaborados e aplicados por meio do Google doc e, ao todo, 27 alunos de diferentes turmas de $1^{\circ}$ ano aceitaram participar da entrevista.

Primeiramente, observou-se que os alunos de primeiro ano de Ensino Médio, leitores de literatura de massa, principalmente de língua estrangeira, frustram suas expectativas quanto às aulas de literatura na escola, cuja finalidade requer um alto grau de especificidade. Segundo as informações obtidas a partir dos questionários, os alunos leem muita literatura fora do ambiente escolar. Ao todo, $100 \%$ dos participantes afirmam que leem textos literários em casa, sendo que, na maioria dos casos, esta literatura se refere à literatura infanto-juvenil, sobretudo de língua estrangeira. Desse modo, ficou evidente que há um descompasso entre as expectativas dos estudantes quanto às leituras trabalhadas nas aulas de literatura e as leituras das quais eles gostam. O resultado deste desencontro fica claro nos gráficos 1 e 2 , a seguir, pois neles se nota que grande parte dos alunos afirmam gostar de literatura (Gráfico 1), mas não da literatura trabalhada na escola, pois a maior parte dos entrevistados afirmou não gostar da literatura ensinada na escola, como aponta o Gráfico 2. Ora, se eles gostam da literatura, a razão de não gostarem da literatura do colégio pode estar relacionada diretamente não só com os textos trabalhados, mas também com as práticas de leitura realizadas com tais textos. 
Gráfico 1 - Alunos que afirmaram gostar de literatura

\section{Alunos que gostam de literatura}

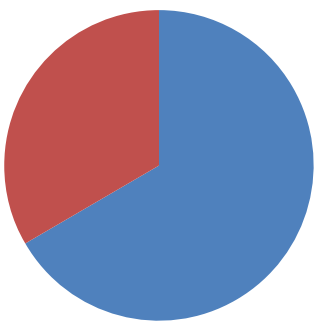

Gráfico 2 - Alunos gostam da literatura na escola

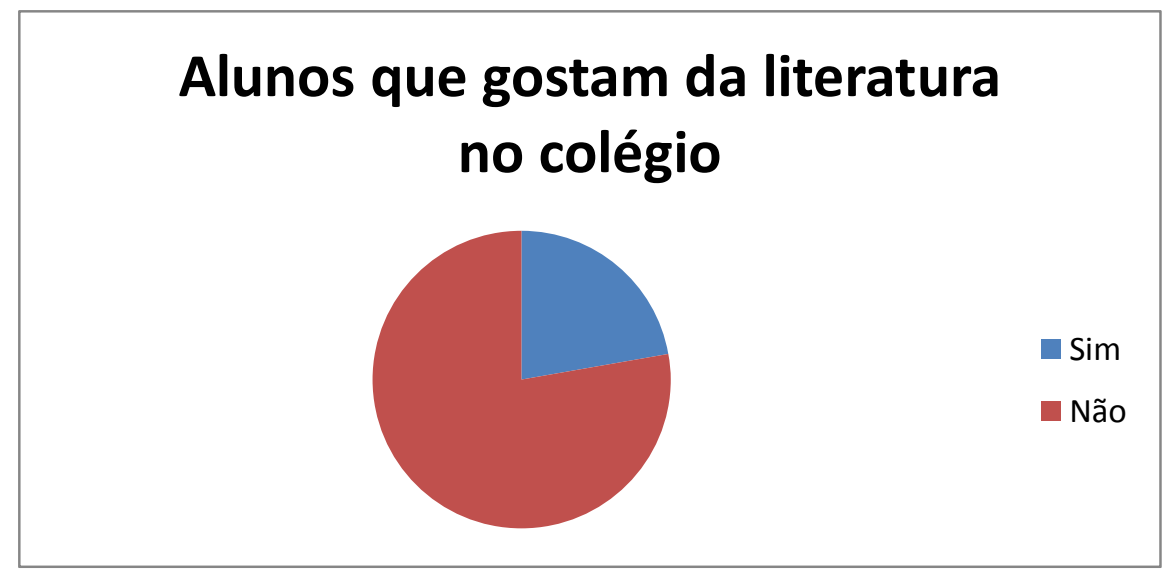

Os entrevistados foram solicitados a elencar as suas últimas leituras de textos literários. Várias obras foram mencionadas, contudo é importante destacar as leituras mais mencionadas entre esses alunos leitores. No Quadro 3, a seguir, estão listados alguns títulos de livros mais citados pelos os alunos participantes da entrevista:

Quadro 3 - Leituras mencionadas pelos alunos entrevistados

\begin{tabular}{|l|c|}
\hline \multicolumn{1}{|c|}{ Obras lidas } & Número de leitores \\
\hline Harry Potter e a pedra filosofal (1997), de J. K. Rowling & 8 \\
\hline As crônicas de gelo e fogo (1996), de George R. Maritin & 7 \\
\hline Um Amor para Recordar (2002), de Nicholas Sparks & 4 \\
\hline Querido John (2010), de Nicholas Sparks & 4 \\
\hline A menina que roubava livros (2007), de Markus Zusak & 3 \\
\hline Capitães de Areia (1937), de Jorge Amado & 2 \\
\hline Dom Casmurro (1899), de Machado de Assis & 2 \\
\hline Iracema (1865), de José de Alencar & 2 \\
\hline TOTAL & 32 citações de textos \\
\hline
\end{tabular}


Com base nessa lista, os livros mais lidos pelos alunos, em sua maioria, tratam de temática infanto-juvenil pertencente ao universo adolescente. Como se pode perceber, os alunos desenvolvem o letramento literário à sua maneira, lendo textos variados, que condizem com as expectativas de leitores adolescentes. Nota-se que a literatura brasileira aparece nas últimas posições da tabela, com dois leitores cada para os textos: Capitães de Areia, de Jorge Amado, Dom Casmurro, de Machado de Assis e Iracema, de José de Alencar. No entanto, é importante considerar que essas obras não pertencem à lista de leituras indicadas pelo colégio para a $1^{\circ}$ série do Ensino Médio. Portanto, não se trata do acatamento por parte desses alunos das indicações da escola. Assim, o que se pode inferir, associando-se esta questão e os gráficos sobre o gosto pela literatura, é que os alunos, efetivamente, consideram como literatura um universo de textos bem maior do que aquele trabalhado na escola que compreende, mais especificamente, os textos canônicos da tradição letrada. Para eles, o termo "literatura" está associado a vários tipos de ficção, sobretudo às narrativas. Ao mesmo tempo, a presença de textos tradicionais como Dom Casmurro ou Iracema evidenciam que os alunos também apreciam os textos clássicos e, nesse sentido, o que justificaria as várias respostas do Gráfico 2, anteriormente apresentado, no qual se nota que os estudantes não gostam da literatura na escola seria o modo como esta é abordada. De fato, a maior parte dos entrevistados considerou as aulas de literatura difíceis. Essas respostas não são difíceis de serem interpretadas, pois como já se salientou, a leitura de textos literários praticada na escola é a leitura literária, ou seja, uma prática de letramento muito específica na qual devem ser levados em conta os artifícios de fingimento do texto, o que implica o conhecimento de vários aspectos estéticos, culturais, textuais e linguísticos que a escola não consegue oferecer ao aluno de modo suficiente para que ele leia literariamente. Por esta razão, a literatura se torna um conteúdo escolar não apreciado e ainda difícil de ser compreendido:

\section{Alunos que acham difíceis as leituras nas aulas de literatura}

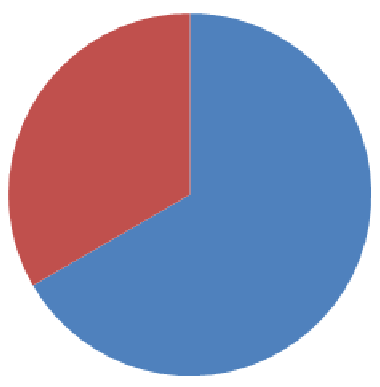


Da mesma forma, quando foram questionados se leem os textos solicitados pelo professor, apenas 30\% dos participantes afirmam ler o texto em sua versão integral. Os demais preferem ler resumos na Internet ou não ler as obras e nem mesmo os resumos. Ora, se 70\% dos alunos não leem os textos indicados pelo professor, pode-se observar que há resistência entre os alunos para interagir com os textos literários exigidos pela escola. Os participantes sugerem que os textos indicados pelo professor são de difícil compreensão e que por essa razão sua leitura é desmotivante. Cabe dizer aqui que as leituras exigidas para estes alunos de $1^{\circ}$ ano de Ensino Médio são aquelas indicadas pela universidade pública da cidade - Universidade Estadual de Maringá, já que esta possui um processo de avaliação seriada, o que leva os professores a elegerem a lista do vestibular desta instituição como leitura obrigatória. Os textos indicados são: Sermões do Pe. Antônio Vieira, Antologia de poemas de Gregório de Mattos, Melhores Poemas de Claudio Manuel da Costa, Marília de Dirceu, Tomaz Antônio Gonzaga.

As difíceis relações entre estudantes e textos literários podem ser observadas de modo mais efetivo quando os alunos foram questionados sobre os tipos de texto que gostariam de trabalhar nas aulas de literatura. Segue a tabela de respostas:

Tabela 1 - Livros que os estudantes gostariam de estudar nas aulas de literatura

\begin{tabular}{l|l|}
\hline \multicolumn{2}{l}{ Quais livros você gostaria que fossem trabalhados ? } \\
\hline Estudante A & Livros mais bem humorados e recentes acho que seria mais interessante. \\
\hline Estudante B & Livros mais atuais que os alunos pudessem demonstrar mais interesse. \\
\hline Estudante C & $\begin{array}{l}\text { Livros com histórias na qual a linguagem seria mais fácil a compreensão, que } \\
\text { pudesse envolver a todos os alunos, pois muitos textos literários são de difícil } \\
\text { compreensão. }\end{array}$ \\
\hline Estudante D & $\begin{array}{l}\text { Livros da autora Agatha Cristie, pois são livros interessantes de investigação e } \\
\text { te prende a leitura. }\end{array}$ \\
\hline Estudante E & $\begin{array}{l}\text { Gostaria que fossem trabalhados livros mais atuais e de literatura estrangeira } \\
\text { também, pois não é todo mundo que gosta dos clássicos da literatura } \\
\text { brasileira, então que, para incentivar a leitura, considero que se deveria utilizar } \\
\text { livros mais leves que os faça ter o hábito da leitura }\end{array}$ \\
\hline Estudante F & Não tenho preferência. \\
\hline Estudante B & Best sellers. \\
\hline Estudante G & A arte da Guerra, O capital, O manifesto comunista que abre o conhecimento. \\
\hline Estudante H & Jogos Vorazes porque faz você querer ler mais. \\
\hline Estudante I & A Bíblia porque envolve história. \\
\hline Estudante J & Os Karas (a saga), ajuda os jovens a pensar um pouco mais além \\
\hline Estudante K & Livros sobre o nazismo, porque acabo me interessando mais pela história. \\
\hline Estudante L & Livros que despertem o gosto nos jovens pela leitura. \\
\hline
\end{tabular}


Com relação aos interesses de leitura dos alunos, um dos entrevistados propôs para as aulas de literatura, "livros com histórias na qual a linguagem seria mais fácil a compreensão, que pudesse envolver a todos os alunos, pois muitos textos literários são de difícil compreensão”. A dificuldade a que este aluno se refere demonstra a carência dos estudantes sobre os protocolos de leitura adequados à leitura literária e sobre os gêneros. Um dos entrevistados diz que "gostaria que fossem trabalhados livros mais atuais e de literatura estrangeira também, pois não é todo mundo que gosta dos clássicos da literatura brasileira, então que, para incentivar a leitura, considero que se deveria utilizar livros mais leves que os faça ter o hábito da leitura”. Na fala destes alunos, percebe-se que as leituras escolares não condizem com o letramento literário por eles praticado e que a escola não está sendo capaz de preparar estes estudantes para a leitura literária, tal como proposta por Hansen (2005), ou seja, uma leitura que seja capaz de levar o leitor ao desvendamento dos artifícios de fingimento do texto e na qual o leitor real possa desempenhar o papel do leitor intratextual imaginado pelo autor.

Essa falta de interação entre o professor e aluno, causada pelo choque entre os letramentos, é definitivamente contraproducente para disciplina de literatura. Muitos alunos demonstram não compreender a razão da disciplina de literatura no currículo escolar, além de não compreenderem a necessidade de estudar obras canônicas, tal como se pôde observar no questionário. Não há um diálogo estabelecido entre os letramentos em jogo, isto é, os letramentos dominantes e vernaculares. Por conseguinte, os alunos, nesse movimento, ficam sem desenvolver o letramento escolar e também sem desenvolver o letramento social de modo questionador, para alcançar aquilo que Rojo (2009) denomina de “letramentos críticos”.

Segundo a autora, os letramentos críticos e protagonistas estão situados no tempo e no espaço. Os significados depreendidos da letra devem ser contextualizados para que o sujeito envolvido possa ler criticamente as várias práticas sociocomunicativas e perceber a sua construção social, o seu propósito, os seus contextos de produção e o significado que ele tem para aqueles leitores:

Tal teorização tem uma implicação prática porque possibilita trabalhar em sala de aula com uma visão de linguagem que fornece artifícios para os alunos aprenderem, na prática escolar, a fazer escolhas éticas entre os discursos que circulam. Isso possibilita aprender a problematizar o discurso hegemônico da globalização e os significados antiéticos que desrespeitem a diferença. (MOITA-LOPES; ROJO, 2004, p. 37-8 apud ROJO, 2008, 108).

Essa postura crítica nas aulas de literatura "possibilita o agenciamento crítico pelo uso da língua com vistas à compreensão dos privilégios 
e apagamentos nas práticas sociais” (DUBOC, 2012, p. 87), de modo que os alunos possam fazer escolhas e entender a importância das práticas letradas instituídas pela agência escolar. A falta de uma postura como essa nas aulas de literatura acarreta choques entre os letramentos, pois os estudantes não são levados a refletir sobre os múltiplos letramentos, ou mesmo, desenvolver o letramento literário escolar. Pelo contrário, eles são conduzidos à perspectiva de um letramento único, completamente descontextualizado e impermeável às várias práticas sociocomunicativas a que os alunos estão expostos. "O aluno precisa ser visto como sujeito da linguagem, que traz a sua história. Ao valorizar as práticas de leitura e escrita do aluno (OLIVEIRA, 2009), os professores podem colaborar para que ele se torne produtor de seus próprios discursos.” ( BEVILAQUA e COLAÇO, 2012, p.29), de maneira que ele possa se posicionar criticamente em relação aos vários discursos que circulam socialmente, inclusive aqueles que são dominantes e esteticamente mais valorizados, como é o caso da literatura ensinada na escola.

\section{Considerações}

Feitas essas considerações, observa-se que a escola se configura enquanto um espaço multíplice e variado, onde convivem os múltiplos letramentos, pois as formas de apropriação da linguagem se dão em inúmeros contextos e os sujeitos não estão alheios a nenhum deles. A escola, cujo objetivo primordial deveria ser proporcionar ao aluno modos de interação com a escrita a fim de contribuir para sua formação e desenvolvimento, levando em conta a heterogeneidade do ambiente escolar, insiste, entretanto, em um ensino descontextualizado que ignora os letramentos literários praticados pelos alunos fora de seus muros e, ao mesmo tempo, não consegue fornecer as ferramentas adequadas para que o aluno leia adequadamente os textos literários por ela eleitos como culturalmente mais importantes.

No campo da leitura literária, deve-se ter em conta que o conceito de letramento literário abrange não somente os textos valorizados pela cultura letrada, como também os vários textos ficcionais que circulam nas diversas esferas sociais. Tendo isso em vista, podemos afirmar que os alunos estão plenamente inseridos em eventos de letramento literário, embora, como se tenha observado, eles reajam contrariamente ao letramento literário escolar. Esta reação negativa dos estudantes em relação às práticas de leitura literária da escola é gerada em virtude de a escola esperar que os estudantes sejam capazes de ler os textos recomendados de maneira uniforme, como se todos os textos pudessem ter o mesmo sentido para todos os tipos de leitores em quaisquer situações.

Essa postura, baseada num ensino descontextualizado, acarreta um confronto entre os letramentos e a consequência disso para o ensino de 
literatura é gravíssima: os estudantes não são levados a desenvolver o letramento escolar, já que reagem contra ele e insistem em práticas de letramento literário de resistência. Este jogo resulta no não desenvolvimento e no não aproveitamento de nenhuma das formas de letramento - nem a escolar, nem a social.

Uma das saídas para esse impasse nas aulas de literatura seria uma mudança metodológica da escola de modo que esta pudesse patrocinar a construção de novos significados para a língua alvo através de uso de textos literários que pertencessem tanto à cultura letrada quanto aqueles pertencentes às culturas diversas dos estudantes, numa abordagem que viabilizasse a desconstrução do texto e reconstrução dos significados, patrocinando um letramento crítico e desconstruindo a concepção polarizada e os choques entre os letramentos.

\section{Referências}

AGUIAR, F. As questões da critica literária. In: Martins, M. H. Outras leituras: literatura, televisão, jornalismo de arte e cultura, linguagens interagentes. São Paulo: Itaú Cultural/Senac, 2000.

BEVILAQUA, R. ;COLAÇO, S. F.. Letramentos na contemporaneidade: perspectivas teóricas. In: PINTO, Cândida Martins; CARVALHO, Evanir Piccolo; COLAÇO, Silvania. (Org.). Projetos de letramento: debates e aplicações. 1ed.: , V.1 , São Vicente do Sul : Instituto Federal Farroupilha, p. 16-32, 2012.

DUBOC, A, P. M. Atitude curricular: letramentos críticos nas brechas na formação de professores de inglês. 2012. 246f. Tese (Doutorado)Faculdade de Filosofia, Letras e Ciências Humanas, Universidade de São Paulo, São Paulo, 2012.

FIGUEIREDO, L. M. S.. O ensino-aprendizagem de língua inglesa como prática de letramento: por uma intervenção híbrida e desestabilizadora. Sinais (UFES), v. 01, p. 27-44, 2009.

HAMILTON, M. Sustainable literacies and the ecology of lifelong learning. In: HARRISON, R. R. F.; HANSON, A.; CLARKE, J. (Orgs.). Supporting lifelong learning. V. 1: Perspectives on learning. London: Routledge; Open University Press, p. 176-187, 2002.

HANSEN, J. A. Reorientações no campo da leitura literária. In: ABREU, M.; SCHAPOCHNIK, N. Cultura letrada no Brasil: objetos e práticas. Campinas: Mercado de Letras, ALB; São Paulo: Fapesp, p. 13-44, 2005.

KLEIMAN, A. B. Introdução: O que é letramento? Modelos de letramento e as práticas de alfabetização na escola. In: (Org.). Os significados do letramento. São Paulo: Mercado de Letras, 2004a. 
Texto e Leitor: Aspectos cognitivos da leitura. Campinas: Pontes, 2004b.

ROJO, R. Letramentos múltiplos, escola e inclusão social. São Paulo: Parábola, 2009.

STREET, B. V. Literacy in theory and practice. Cambridge: Cambridge University Press, 1984.

ZAPPONE, M. H. Y. Modelos de letramento literário e ensino da literatura: problemas e perspectivas. Teoria e Prática da Educação, v. 03, p. 47-62, 2007.

Fanfics: uma caso de letramento literário na cibercultura?.

Letras de Hoje, v. 43, p. 29-33, 2008.

A leitura literária e suas especificidades. In: Mirian Hisae Yaegashi Zappone. (Org.). Leitura do texto literário: práticas e letramentos. 1ed., Maringá: Eduem, 2010, v. 1, p. 11-26, 2010.

Recebido em 18/10/2013

Aprovado em 08/02/2014 